\title{
Isolation of Amidase-negative Mutants of Pseudomonas aeruginosa Using Glycollamide as a Selective Agent
}

\author{
By P. R. BROWN* AND RENÉE TATA \\ Department of Biochemistry, King's College London, Strand, London WC2R 2LS, UK
}

(Received 26 August 1986; revised 8 January 1987)

A positive selection is described for isolating amidase-negative mutants from Pseudomonas aeruginosa strains. The method is based on the conversion, via amidase activity, of glycollamide to glycollate which is growth inhibitory. Three types of mutant were isolated on lactate medium containing glycollamide: (i) mutants in which amidase activity was reduced or absent; (ii) double mutants that were amidase-negative and resistant to glycollate inhibition of growth; and (iii) glycollate-resistant mutants. By raising glycollamide concentrations in the selection medium, amidase-negative mutants were obtained from strains producing altered amidases with low specific acetamidase and glycollamidase activities. Glycollamide has wider applicability than fluoroacetamide as a selective agent for obtaining amidase-negative mutants.

\section{INTRODUCTION}

The inducible aliphatic amidase acylamide amidohydrolase (EC 3.5.4.1) of Pseudomonas aeruginosa catalyses the hydrolysis of a limited number of aliphatic amides. Amides that act as substrates and inducers of amidase such as acetamide and propionamide can provide the sole source of carbon and nitrogen for growth of the organism (Kelly \& Clarke, 1962). Formamide, a substrate but non-inducer of the enzyme, has been used as a nitrogen source in the selection of mutants that produce the enzyme constitutively (Brammar et al., 1967). Synthesis of the enzyme is sensitive to catabolite repression, succinate causing a pronounced reduction in synthesis, lactate a weaker effect; the highest levels of enzyme synthesis are obtained during growth in medium containing pyruvate as carbon source (Smyth \& Clarke, 1975). Several mutant strains have been isolated that are able to grow on media containing as carbon or nitrogen sources amides such as butyramide, valeramide, acetanilide and phenylacetamide that are poor substrates for the wild-type amidase; these strains produce altered amidases with increased activity towards the amide used in the selection medium (Brown et al., 1969; Brown \& Clarke, 1972; Betz et al., 1974). Clarke \& Tata (1973) described a positive selection method for isolating amidase-negative mutants using fluoroacetamide as the selective agent. This compound is a substrate for amidase but not an inducer (Kelly \& Clarke, 1962) and the product of amidase activity, fluoroacetate, is toxic to the organism. Amidase-negative mutants were obtained by Clarke \& Tata (1973) as survivors after incubation of $P$. aeruginosa strains on growth media that allowed maximum expression of amidase activity and contained fluoroacetamide. The method has been used to isolate amidase-negative mutants both from strains that are constitutive and from those that are inducible for the synthesis of normal amidase (Rehmet \& Shapiro, 1983). However, we have had no success in applying the method to isolate amidase-negative mutants from strains producing altered amidases. Even though conditions in the selection medium have been chosen to maximize fluoroacetate production by raising fluoroacetamide concentrations to $15 \mathrm{mg} \mathrm{ml}^{-1}$ and using pyruvate as carbon source, background growth remains substantial (P. R. Brown \& R. Tata, unpublished observations). This prompted us to develop a new method for the 
Table 1. P. aeruginosa strains

\begin{tabular}{ll} 
Strain & \multicolumn{1}{c}{$\begin{array}{c}\text { Class of amidase } \\
\text { mutant }\end{array}$} \\
8602 & Wild-type \\
L10 & Constitutive, crp \\
C11 & Constitutive \\
B6 & Constitutive, altered amidase \\
AI3 & Constitutive, altered amidase \\
AIUIN & Constitutive, altered amidase
\end{tabular}

\author{
Parent strain/ \\ isolation medium $(\mathrm{C} / \mathrm{N})^{*}$ \\ $8602 /$ (succinate/lactamide) \\ $8602 /$ (succinate/formamide) \\ C11/(butyramide) \\ L 10/(acetanilide/ $\mathrm{NH}_{4}^{+}$) \\ AI3/(acetanilide/urea)
}

\section{Reference}

Kelly \& Clarke (1962)

Smyth \& Clarke (1975)

Brammar et al. (1967)

Brown et al. (1969)

Brown \& Clarke (1972)

Gregoriou et al. (1977)

* Sources of carbon and nitrogen.

isolation of amidase-negative mutants from such strains. The basis for the method is our observation that glycollate acts as a growth inhibitor of $P$. aeruginosa on lactate medium (Brown \& Tata, 1987) and, since glycollamide is a substrate for amidase (Kelly \& Clarke, 1962), inhibition of growth of strains with amidase activity might be expected on lactate medium in the presence of glycollamide whereas mutants without amidase activity should grow. A preliminary report on this work has appeared previously (Brown \& Tata, 1981).

\section{METHODS}

Bacterial strains. The wild-type strain used was Pseudomonas aeruginosa 8602 (PAC 1), (Kelly \& Clarke, 1962) obtained from NCIB (Aberdeen, UK). The other P. aeruginosa strains harboured mutations affecting amidase synthesis and/or structure and their properties and origins are summarized in Table 1.

Media. These were prepared by appropriate additions to minimal salt medium (Brammar \& Clarke, 1964). All media except acetamide medium contained $0 \cdot 1 \%(\mathrm{w} / \mathrm{v})\left(\mathrm{NH}_{4}\right)_{2} \mathrm{SO}_{4}$ as nitrogen source. Succinate medium contained $0.5 \%(\mathrm{w} / \mathrm{v})$ sodium succinate, lactate medium contained $0.3 \%(\mathrm{w} / \mathrm{v})$ sodium DL-lactate, lactate/glycollamide medium contained $0.05 \%(\mathrm{w} / \mathrm{v})$ sodium DL-lactate and glycollamide at the concentrations indicated in Results. Glycollate/lactate medium contained $0.05 \%(\mathrm{w} / \mathrm{v})$ sodium DL-lactate and $0.2 \%(\mathrm{w} / \mathrm{v})$ sodium glycollate. Glycollate medium used in the isolation of LIC mutants contained $0.1 \%(\mathrm{w} / \mathrm{v})$ sodium glycollate. Glycollamide medium contained $0.1 \%(\mathrm{w} / \mathrm{v})$ glycollamide. Acetamide medium contained $0.1 \%(\mathrm{w} / \mathrm{v})$ acetamide. Succinate, lactate and $\left(\mathrm{NH}_{4}\right)_{2} \mathrm{SO}_{4}$ were added to media before autoclaving. Solutions of all other compounds were sterilized by filtration and added to media after autoclaving. Solid media contained $1 \%$ (w/v) Difco Noble Agar.

Bacterial growth. Organisms were normally grown in $300 \mathrm{ml}$ culture medium in 11 conical flasks in a Gallenkamp rotary shaker at $37^{\circ} \mathrm{C}$. Growth was monitored by removing samples and measuring the $\mathrm{OD}_{670}$ in a Unicam SP600 spectrophotometer. To prepare extracts, cells were harvested by centrifugation, washed with dilution buffer (Brammar et al., 1967), resuspended in $3 \mathrm{ml} 50 \mathrm{~mm}-\mathrm{Tris} / \mathrm{HCl}$ buffer, $\mathrm{pH} 7 \cdot 0$, and sonicated for $1 \mathrm{~min}$ at $0^{\circ} \mathrm{C}$ using an MSE Mullard ultrasonic disintegrator (power output $50 \mathrm{~W}$ ). Cell debris was removed by centrifugation at $12000 \mathrm{~g}$ for $15 \mathrm{~min}$. Protein was estimated by the method of Lowry using bovine serum albumin as standard.

Isolation of mutants. Cultures were grown overnight at $37^{\circ} \mathrm{C}$ in $5 \mathrm{ml}$ Oxoid Nutrient Broth no. 2, washed with dilution buffer and resuspended in $5 \mathrm{ml}$ of dilution buffer; portions $(0.1 \mathrm{ml})$ were then spread on the selection medium. After $24-48 \mathrm{~h}$ incubation mutant colonies were normally restreaked to obtain single colonies on the selection plate, though occasionally, when appropriate, mutants were patched directly onto glycollate/lactate and acetamide solid media.

Enzyme assays. Assays for amide hydrolase activity were done by measuring the rate of ammonia release from substrate amides using glutamate dehydrogenase as a linking enzyme (Gregoriou \& Brown, 1979). Amide concentrations of $0.1 \mathrm{M}$ were normally used in the reaction mixtures. Amidases produced by strains AI 3 and AIUIN were also assayed using $p \mathrm{NO}_{2}$-acetanilide as substrate as described by Gregoriou et al. (1977). NAD ${ }^{+}$ independent lactate dehydrogenase (iLDH) was assayed as described by Brown \& Tata (1987).

Chemicals. Glycollamide was prepared by the ammoniolysis of glycollic acid ethyl ester (Schmuck, 1924); glycollic acid was obtained from BDH; fluoroacetamide was obtained from Hopkins and Williams. All three chemicals were recrystallized twice from ethanol before use.

\section{RESULTS}

Growth inhibition by glycollamide

To test the feasibility of using glycollamide as a selective agent for the isolation of amidasenegative mutants, its effects on the growth of strain L10, which produces amidase constitutively, 

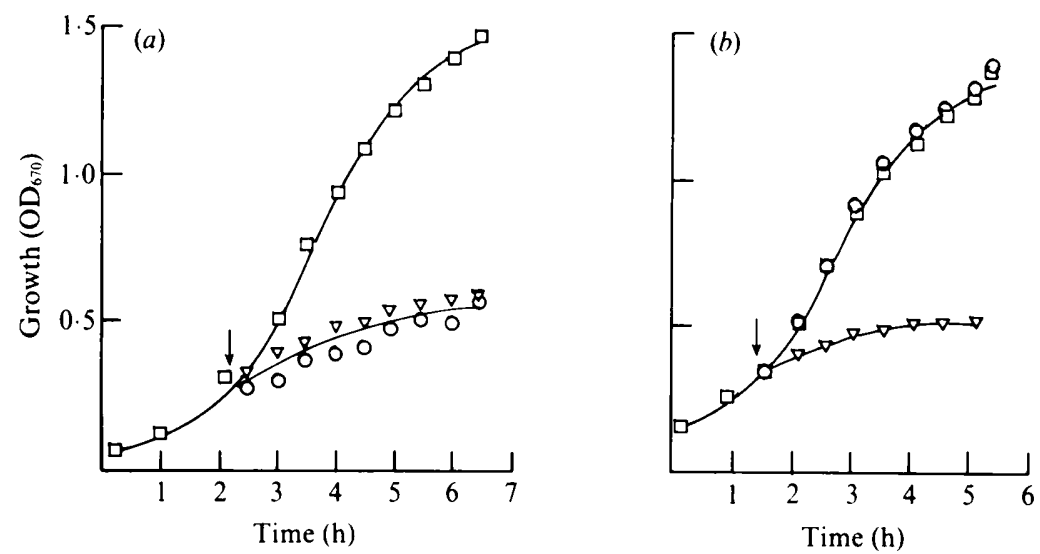

Fig. 1. Effects of glycollamide and glycollate on growth of $P$. aeruginosa strains L10 (amidase-positive) (a) and KLAm 38 (amidase-negative) (b). Bacteria were grown in lactate $/ \mathrm{NH}_{4}^{+}$medium at $37^{\circ} \mathrm{C}$. Portions $(45 \mathrm{ml})$ were transferred at the times indicated by the arrows to $250 \mathrm{ml}$ flasks containing $5 \mathrm{ml}$ $39 \mathrm{~mm}$-glycollate $(\nabla), 39 \mathrm{~mm}$-glycollamide $(O)$ or water $(\square)$ at $37^{\circ} \mathrm{C}$.

and a spontaneous amidase-negative mutant (KLAm38) obtained from strain L10 by the fluoroacetamide method (P. R. Brown \& R. Tata, unpublished) were compared. Strain L10 harbours an additional, unlinked, mutation that confers reduced sensitivity to catabolite repression (Smyth \& Clarke, 1975). Cells were grown to early exponential phase in lactate medium and glycollamide $\left(3 \mathrm{mg} \mathrm{ml}^{-1}\right)$ was added; growth of the amidase-positive but not of the amidase-negative strain was inhibited (Fig. 1). It was concluded that the different response to glycollamide was due to the absence of amidase in the mutant. Furthermore, both strains were equally sensitive to growth inhibition by glycollate when this compound was added to cells growing in lactate medium (Fig. 1). Thus conversion of glycollamide to glycollate was required for growth inhibition to occur.

\section{Mutants from strains synthesizing amidase constitutively}

Plating $10^{8}$ cells of an overnight culture of strain L10 on lactate medium containing glycollamide $\left(2 \mathrm{mg} \mathrm{m} !^{-1}\right)$ produced approximately 200 mutant colonies with no visible background after overnight incubation at $37^{\circ} \mathrm{C}$. The growth properties of these mutants were tested by patching and the majority grew on acetamide medium but differed from the parent strain in growing on glycollate/lactate medium. We concluded, tentatively, that these mutants had acquired resistance to glycollamide by gaining resistance to glycollate rather than through loss of amidase activity. When the glycollamide concentration in the selection plate was increased to $5 \mathrm{mg} \mathrm{ml}^{-1}$ two types of mutant were obtained. A few colonies were visible after $24 \mathrm{~h}$ incubation at $37^{\circ} \mathrm{C}$, and after another $24 \mathrm{~h}$ a further 100 slower-growing colonies were visible. Patch tests showed that the faster-growing colonies were unable to grow on acetamide medium but grew on glycollate/lactate medium whereas the slower-growing colonies grew on both. The same two phenotypes were obtained using another strain, $\mathrm{Cl1}$, as parent. Amidase synthesis in this strain, although constitutive, is sensitive to catabolite repression (Smyth \& Clarke, 1975).

Cell free extracts from randomly selected representatives of the two types of mutant obtained from strains $\mathrm{Cl} 1$ and $\mathrm{L} 10$ were prepared from cells grown in lactate medium. Assays confirmed that the faster-growing mutants had no amidase activity whereas in the slower-growing strains amidase activity appeared unaffected. Cell-free extracts from the same selection of mutants were prepared from cells grown in succinate medium and assays for iLDH activity established that for both types of mutant, synthesis was constitutive (data not shown; summary in Table 3). In the accompanying paper (Brown \& Tata, 1987) we report that resistance to inhibition by glycollate of growth on lactate medium is associated with mutations that result in constitutive 
Table 2. Acetamidase and glycollamidase activities of $P$. aeruginosa mutant strains

\begin{tabular}{|c|c|c|}
\hline \multirow{2}{*}{$\begin{array}{l}\text { Mutant } \\
\text { strain }\end{array}$} & \multicolumn{2}{|c|}{$\begin{array}{c}\text { Amidase specific activity* } \\
{\left[\mu \mathrm{mol} \mathrm{NH}{ }_{3} \min ^{-1}(\mathrm{mg} \text { protein })^{-1}\right]}\end{array}$} \\
\hline & Glycollamidase & Acetamidase \\
\hline L10 & $19 \cdot 7$ & $12 \cdot 7$ \\
\hline Cl1 & 8.7 & $6 \cdot 3$ \\
\hline B6 & $10 \cdot 0$ & $8 \cdot 1$ \\
\hline $\mathrm{AI} 3$ & $5 \cdot 8$ & $2 \cdot 1$ \\
\hline AIUIN & 0.33 & 0.7 \\
\hline
\end{tabular}

- This was measured in extracts of cells grown in lactate medium by the glutamate dehydrogenase coupled assay as described in Methods.

synthesis of iLDHs. The amidase-negative mutants were therefore apparently harbouring two mutations, one preventing synthesis of active amidase, the other causing constitutive synthesis of iLDHs. Acetamide-utilizing, amidase-positive revertants, obtained from a selection of amidase-negative, glycollate-resistant, mutant strains retained the glycollate-resistant phenotype, providing a further indication that two independent mutations accounted for the phenotypic properties in these cases.

\section{Mutants from strains producing altered amidases}

Strains B6, AI3, and AIU1N derived either from strain $\mathrm{Cl1}$ or $\mathrm{L10}$, all constitutive for amidase synthesis and each producing an altered amidase, were used as parent strains in the isolation of amidase-negative mutants. For each of these organisms the specific amidase activities of cell-free extracts with respect to acetamide and glycollamide were less than for strains $\mathrm{L} 10$ or $\mathrm{C} 11$ although, with the exception of strain AIU $1 \mathrm{~N}$ which had the lowest activity of all towards both substrates, activity was greater with glycollamide as substrate than with acetamide (Table 2). Initial attempts to isolate amidase-negative mutants were made using the isolation medium containing glycollamide $\left(5 \mathrm{mg} \mathrm{ml}^{-1}\right)$ that had been used successfully with strains L10 and C11. Strain B6 produced mutant colonies with no background growth but for strains AI3 and AIU1N, background growth was too great to allow any mutants to be discerned or isolated easily. However, by increasing glycollamide concentration in the selection medium, background growth was sufficiently inhibited for mutants to be isolated from both of these strains. Even at $15 \mathrm{mg}$ glycollamide $\mathrm{ml}^{-1}$ some background growth was observed with strain AIU1N but mutants were clearly visible and could easily be purified by restreaking to obtain single colonies on the selection medium. It appeared then that the weaker the glycollamidase activity of the organism the higher the concentration of glycollamide required to suppress background (parental) growth. Mutants from all strains were examined for amidase activity and glycollate resistance and the properties of a selection are shown in Table 3. Mutants fell into three groups: those that had no or reduced amidase activity; those that were glycollate resistant through constitutive production of iLDH; and those that combined the properties of the other two groups. Mutants in which amidase activity had been affected were generally easily discernible on the selection media by their large colony size. In some cases mutant colonies were shown, by streaking on acetamide medium, to contain a mixture of amidase-positive and amidase-negative cells, the latter producing shadowy colonies on acetamide medium. Both types of cell were glycollate-resistant, suggesting that an initial mutational event causing glycollate resistance had given a slight growth advantage and a second mutation to amidase-negativity provided additional resistance to glycollamide. Most of the AIUIN amidase-negative mutants had, however, retained sensitivity to glycollate.

For the wild-type strain 8602 , glycollamide is a weak inducer of amidase synthesis, approximately 10 -fold less effective than acetamide (Kelly \& Clarke, 1962), so it was not surprising that relatively high concentrations of glycollamide $\left(15 \mathrm{mg} \mathrm{ml}^{-1}\right)$ were required to suppress background growth and obtain amidase-negative mutants. 
Table 3. Summary of properties of mutant strains of $P$. aeruginosa isolated on glycollamide/lactate medium

\begin{tabular}{|c|c|c|c|c|c|}
\hline \multirow[b]{2}{*}{$\begin{array}{c}\text { Bacterial } \\
\text { strains }\end{array}$} & \multirow[b]{2}{*}{$\begin{array}{l}\text { Growth } \\
\text { medium }\end{array}$} & \multicolumn{2}{|c|}{ Growth properties* } & & \\
\hline & & 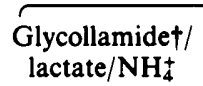 & $\begin{array}{c}\text { Glycollate/ } \\
\text { lactate/NH }\end{array}$ & Acetamide & Phenotypef \\
\hline
\end{tabular}

Parent strains

L10, B6, C11

A13, AIU1N, 8602

\begin{tabular}{|c|c|c|c|}
\hline- & - & + & $\begin{array}{l}\text { Am }^{+} \text {, inducible } \\
\text { iLDH }\end{array}$ \\
\hline+ & + & + & $\begin{array}{l}\text { Am }{ }^{+} \text {, constitutive } \\
\text { iLDH }\end{array}$ \\
\hline+ & - & - & $\begin{array}{l}\mathrm{Am}^{-} \text {, inducible } \\
\text { iLDH }\end{array}$ \\
\hline+ & + & - & $\begin{array}{l}\text { Am }^{-}, \text {constitutive } \\
\text { iLDH }\end{array}$ \\
\hline
\end{tabular}
$+$
$\mathrm{Am}^{+}$, inducible iLDH

Mutant strains $\S$

A13(F), AIU1N(B)

Al3(I), AIU1N(A), B6(4)

AIU1N(A), 8602(A), C11(1)

$*+$, Single colonies after $24 \mathrm{~h}$ at $37^{\circ} \mathrm{C}$; - , no colonies or shadowy colonies $\left(\mathrm{Am}^{-}\right)$after $48 \mathrm{~h}$ at $37^{\circ} \mathrm{C}$.

+ Mutants from strains L10, B6 and $\mathrm{C} 11$ were isolated on medium containing $5 \mathrm{mg}$ glycollamide $\mathrm{ml}^{-1}$. Mutants from strains $8602, \mathrm{Al} 3$ and AIUIN were obtained on medium containing $15 \mathrm{mg}$ glycollamide $\mathrm{ml}^{-1}$.

‡ These were based on enzyme assays. Assays for amidase (Am) activity were done on cells grown in lactate medium (with $0.1 \mathrm{M}$-acetamide as inducer for 8602-derived strains), using glycollamide and acetamide as substrates for mutants derived from strains $8602, \mathrm{~L} 10, \mathrm{Cll}$ and $\mathrm{B} 6$ and using $p \mathrm{NO}_{2}$-acetanilide for mutants derived from strains AI3 and AIUIN. iLDH assays were done on strains grown in succinate medium. Strains producing detectable iLDH (normally about $20 \%$ of the activity in lactate-grown cells) were deemed iLDH constitutive.

$\S$ Mutant strains chosen arbitrarily to illustrate the three basic types obtained.

\section{Isolation of amidase-negative mutants from glycollate-utilizing strains}

Mutants (LIC strains), obtained from strain L10, selected for their ability to grow slowly with glycollate as carbon source (M. W. W. Adams \& P. R. Brown, unpublished) were nonetheless unable to grow with glycollamide as carbon source. Glycollamide-utilizing mutant colonies obtained from these strains by plating $10^{8}$ cells of strain LIC6 on glycollamide medium contained both amidase-positive cells and cells in which amidase activity was substantially reduced or absent (data not shown). Amidase-negative mutants obtained by this method were lost when the original mutant colonies were streaked back on the isolation medium indicating that they were probably sustained on the selection plate by cross-feeding from the associated amidase-positive cells. The amidase-negative mutants were therefore purified by streaking on acetamide medium and selecting the shadowy colonies. Attempts to obtain amidase-negative mutants from strain AIUIN by a similar indirect route (first obtaining a glycollate-utilizing mutant then plating it on glycollamide medium) failed because the glycollate-utilizing strain (synthesizing AIU1N amidase) grew too well for faster-growing mutants to be distinguished. No attempt was made in this case to investigate the effects of increasing the glycollamide concentration.

\section{$K_{m}$ values of amidases for fluoroacetamide and glycollamide}

Since raising fluoroacetamide concentrations (up to $15 \mathrm{mg} \mathrm{ml}^{-1}$ ) did not suppress growth of the strains producing altered amidases whereas increasing glycollamide concentrations did, it seemed possible that this might reflect differences in the relative affinities of the amidases for fluoroacetamide and glycollamide. $K_{\mathrm{m}}$ values were therefore determined for the two substrates using purified amidases and the results, given in Table 4, clearly showed that $K_{\mathrm{m}}$ values for fluoroacetamide were lower than those for glycollamide. Furthermore, inhibition of AI3 amidase activity by fluoroacetamide concentrations above $100 \mathrm{~mm}$ was observed.

\section{Properties of amidase mutants}

Amidase-negative mutants were examined to see if the selection method had favoured any particular kind of mutation. Rates of reversion to amidase-positive measured by the frequency 
Table 4. Comparison of $K_{m}$ values for fluoroacetamide and glycollamide of purified amidases from $P$. aeruginosa $P A C I$ mutant strains

\begin{abstract}
Amidases were purified as described by Gregoriou \& Brown (1979). $K_{\mathrm{m}}$ values ( $\pm \mathrm{SE}$ ) were determined using a computer program to fit initial rate data to a rectangular hyperbola (A. Heaton \& P. R. Brown, unpublished). Where $V_{\max }$ values could be determined they were the same for glycollamide and fluoroacetamide for individual enzymes [L10, $V_{\max }$ (fluoroacetamide/glycollamide) $=1.6 \mathrm{mmol} \mathrm{NH}_{3}$ released $\min ^{-1}(\mathrm{mg} \text { enzyme })^{-1} ; \mathrm{B6}, V_{\max }$ (fluoroacetamide/glycollamide) $=430 \mu \mathrm{mol} \mathrm{NH}_{3}$ released $\min ^{-1}$ (mg enzyme) $)^{-1}$.
\end{abstract}

\begin{tabular}{|c|}
\hline $\begin{array}{c}\text { Strain } \\
\text { (source of amidase) }\end{array}$ \\
\hline $\begin{array}{l}\text { L10 } \\
\text { B6 } \\
\text { AI3 } \\
\text { AIU1N }\end{array}$ \\
\hline
\end{tabular}

$\overbrace{\text { Glycollamide }}^{K_{\mathrm{m}}(\mathrm{mM})} \begin{array}{cc}\text { Fluoroacetamide } \\ 409 \pm 55 & 40 \pm 15 \\ 326 \pm 43 & 60 \pm 16 \\ -* & 80 \pm 16 \dagger \\ \text {-* } & \text { ND }\end{array}$

\footnotetext{
* Values were above the solubility limits for glycollamide and could not be accurately obtained (Gregoriou \& Brown, 1979).

+ Substrate inhibition was observed at concentrations above $100 \mathrm{~mm}$. Initial rate data for substrate concentrations above this value were not included in $K_{m}$ determinations.
}

of occurrence of acetamide-utilizing cells in the population in the absence and presence of a range of chemical mutagens varied from mutant to mutant; some gave no revertants at all, indicating that the mutations were probably deletions. Some of the mutants produced material cross-reacting with antiserum to the wild-type amidase so these were presumed to be structural gene mutants. We concluded from these observations that the mutations represented a range of different types and had occurred in different parts of the amidase operon.

\title{
DISCUSSION
}

Glycollamide has proved more useful than fluoroacetamide as a selective agent to isolate spontaneous mutants of $P$. aeruginosa altered in their ability to synthesize amidase, because it is effective with strains synthesizing amidase with low specific acetamidase activities whereas fluoroacetamide is not. An additional advantage of glycollamide is that it is less hazardous to handle than fluoroacetamide. Both the fluoroacetamide and glycollamide methods were based on favouring the growth of those cells which were unable to convert the respective amide through the action of amidase into a product toxic to the cell. On either fluoroacetamide- or glycollamide-containing media, increased bacterial growth is observed under conditions in which amidase activity is reduced. Farin (1977) concluded that $P$. aeruginosa is freely permeable to amides, suggesting that the resistance of strains with low amidase activity to growth inhibition by fluoroacetamide and glycollamide results from reduced intracellular concentrations of toxic derivatives due to the reduced uptake rates for the two compounds. The effectiveness of raising the concentration of glycollamide in suppressing growth therefore probably reflects the relatively high $K_{\mathrm{m}}$ values for glycollamide of the amidases produced by each of the strains used in this study. Glycollamide concentrations of $15 \mathrm{mg} \mathrm{m}^{-1}$ fall below the lowest of the $K_{\mathrm{m}}$ values of any of the amidases for this substrate. In contrast, since $K_{\mathrm{m}}$ values for fluoroacetamide are considerably lower than for glycollamide, increasing the fluoroacetamide concentration in the selection medium would not be expected to have as relatively large an influence on amidase activity as increasing the glycollamide concentration. In addition, substrate inhibition observed at fluoroacetamide concentrations above $100 \mathrm{~mm}$ may also contribute to the ineffectiveness of fluoroacetamide in inhibiting growth of strain AI3.

The selection method involving glycollamide will only be applicable to strains in which glycollate acts as an inhibitor of growth. We do not know how widespread this phenomenon is among bacteria, but it may occur with most fluorescent pseudomonads as only a small 
proportion are able to use glycollate as a growth substrate (Stanier et al., 1966). However, growth inhibition of LIC mutants by glycollamide indicates that the rate of uptake or utilization of glycollate might be a critical factor in determining sensitivity to glycollamide in some cases.

\section{REFERENCES}

Betz, J. L., Brown, P. R., Smyth, M. J. \& Clarke, P. H. (1974). Evolution in action. Nature, London 247, 261-264.

Brammar, W. J. \& Clarke, P. H. (1964). Induction and repression of Pseudomonas aeruginosa amidase. Journal of General Microbiology 37, 307-319.

Brammar, W. J., Clarke, P. H. \& Skinner, A. J. (1967). Biochemical and genetic studies with regulator mutants of the Pseudomonas aeruginosa 8602 amidase system. Journal of General Microbiology 47, 87-102.

Brown, J. E., Brown, P. R. \& Clarke, P. H. (1969). Butyramide-utilizing mutants of Pseudomonas aeruginosa 8602 which produce an amidase with altered substrate specificity. Journal of General Microbiology 57, 273-285.

Brown, P. R. \& Clarke, P. H. (1972). Amino acid alteration in an amidase produced by an acetanilideutilizing mutant of Pseudomonas aeruginosa. Journal of General Microbiology 70, 287-298.

Brown, P. R. \& TATA, R. (1981). Mutants of Pseudomonas aeruginosa resistant to growth inhibition by glycollamide. Biochemical Society Transactions 9(2), 306P.

BRown, P. R. \& TATA, R. (1987). Glycollate inhibition of growth of Pseudomonas aeruginosa on lactate medium. Journal of General Microbiology 133, 15211526.

Clarke, P. H. \& TATA, R. (1973). Isolation of amidasenegative mutants of Pseudomonas aeruginosa by a positive selection method using an acetamide ana- logue. Journal of General Microbiology 75, 231-234.

FARIN, F. (1977). Studies on the mechanism of regulation of amidase synthesis in Pseudomonas aeruginosa. $\mathrm{PhD}$ thesis, University of London, UK.

Gregoriou, M. \& Brown, P. R. (1979). Inhibition of the aliphatic amidase from Pseudomonas aeruginosa by urea and related compounds. European Journal of Biochemistry 96, 101-108.

Gregoriou, M., Brown, P. R. \& TATA, R. (1977). Pseudomonas aeruginosa mutants resistant to urea inhibition of growth on acetanilide. Journal of Bacteriology 132, 377-384.

Kelly, M. \& Clarke, P. H. (1962). An inducible amidase produced by a strain of Pseudomonas aeruginosa. Journal of General Microbiology 27, 305316.

Rehmet, S. \& Shapiro, J. A. (1983). Insertion and replication of the Pseudomonas aeruginosa mutator phage D3112. Molecular and General Genetics 192, 416-423.

ScHMUCK, A. (1924). Die Verkettungsreaktion der Amide von $\alpha$-oxysaüren. Biochemische Zeitschrift 147, 193-202.

Smyth, P. F. \& Clarke, P. H. (1975). Catabolite repression of Pseudomonas aeruginosa amidase: the effect of carbon source on amidase synthesis. Journal of General Microbiology 90, 81-90.

Stanier, R., Palleroni, N. J. \& Doudoroff, $M$. (1966). The aerobic pseudomonads: a taxonomic study. Journal of General Microbiology 43, 159271 . 